\title{
Editors’ Address
}

\author{
Dierk Vorwerk
}

Published online: 6 March 2010

(C) Springer Science+Business Media, LLC and the Cardiovascular and Interventional Radiological Society of Europe (CIRSE) 2010

Dear Readers,

For the past 5 years, Prof. Ziv Haskal has filled the role of Deputy-Editor-in-Chief for CVIR. Earlier this year, he left the editorial team of CVIR to become Editor-in-Chief for JVIR, our American sister journal. The editors of CVIR would like to take this opportunity to warmly thank Ziv for the excellent work he has performed for this journal-for his highly appreciated input, his dedication and his outstanding professionalism.

Ziv's promotion to become Editor-in-Chief of JVIR is, without a doubt, a reflection of the wonderful job he did for CVIR, which is the oldest journal in the field of interventional radiology. We at CVIR are proud that one of our editorial members was selected for this challenging but honorable position.

As Ziv's new appointment arrived with relatively short notice, reorganization of the editorial team will take some time. However, one newly established development that we are proud to present is the appointment of Shandra Bipat, Ph.D. (Amsterdam) to our board of editors, as a specialist in statistics. We have long desired to have an expert statistician on our team, and we are very happy to have found Dr. Bipat. To Dr. Bipat we say, "Welcome aboard" and to Dr. Haskal, we say, "Congratulations."

D. Vorwerk ( $\square)$

Department of Radiology, Klinikum Ingolstadt, Ingolstadt, Germany

e-mail: dierk.vorwerk@klinikum-ingolstadt.de 